\title{
THE EFFECT OF USING DIFFERENT LOCATOR ATTACHMENTS WITH A DIFFERENT RETENTION VALUE ON THE BONE HEIGHT CHANGES IN IMPLANT SUPPORTED CLASS I REMOVABLE MANDIBULAR PARTIAL OVERDENTURE, A RADIOGRAPHIC EVALUATION
}

\author{
Amr Salah El-Din* and Ahmed Mohamed Osama**
}

\begin{abstract}
Purpose: The aim of this study was to evaluate the effect of using different locator attachments with a different retention value and ball and socket attachment on the bone height changes in Implant Supported class I removable Mandibular partial Overdenture.

Introduction: The use of osseointegrate dental implants is one of the most successful treatment options to solve the problem of distal extension cases. A critical factor affecting the success of an implant is the manner in which mechanical stresses are transferred from the implant to the bone. One of the factors which affect the amount of force transmitted to the implant is the choice of the attachment. The Locator attachment system is a self-aligning and has dual retention, supplied in different colors; with a different retention value (white, orange and blue). The white housing has light retention, the orange housing has standard retention, and the blue has high retention while the ball and socket attachments consist of a titanium male unit and an easily replaceable rubber ring female unit that is retained in a metal retainer ring. The question is which of the various Locator attachment system used to retain mandibular partial overdenture affect the magnitude of stresses transmitted to the implants thus affecting the bone height changes around the implants.
\end{abstract}

Material and methods: Twelve class I mandibular partially edentulous patients with opposing full dentate maxillary arch were selected from the from the Outpatient clinic, Prosthodontic Department, Faculty of Dentistry, Ain shams University. For all the patients extra and intraoral examinations were done associated with the proper laboratory investigations. Acrylic temporary partial denture was made for all the patients, the partial denture was duplicated into clear acrylic resin model then the model was scanned using CBCT machine and the DICOM data was processed to obtain STL file for the model. The digital image was performed and the virtual implant was placed in the most optimal position at the first molar area according to the surgical and prosthetic design.

* Lecturer of Removable Prosthodontics, Fayoum University.

** Associate Professor of Removable Prosthodontics, Faculty of Dentistry- Ain shams University. 
Conventional implant fixture were surgically inserted so that the top level of fixture needs to be located $0.5 \mathrm{~mm}$ below the marginal crestal bone level, After three month from implant insertion, each patient was recalled For the insertion of super structure. The selected cases were randomly divided into three equal groups; Group I received an implant Supported class I removable Mandibular partial Overdenture with white locator attachment Group II received a Implant Supported class I removable Mandibular partial Overdenture with an orange locator attachment and Group III received an implant Supported class I removable Mandibular partial Overdenture with a ball and socket attachment.

CBCT was used to evaluate the bone height changes around each implant at time of partial over denture insertion, 6months and 12 months from partial over denture insertion.

Results: The results show that in all groups the bone loss appeared to be within acceptable limits in the groups during follow up period(less than $1 \mathrm{~mm}$ during first year) but with significant differences in the bone height changes around the implant between both locator attachments and ball and socket attachment while the results show no significant difference between white and orange locator but the orange locator show higher bone resorption than the white locator.

Conclusion: The current study concluded that locator attachments with different retention value provides better preservation of crestal bone than ball and socket stud attachment, where the white locator attachment show transmits less stress to the abutment resulting in reducing the amount of bone loss around the implants than orange locator when used in implant supported class I mandibular partial over denture

KEYWORDS: Implant Overdenture, ball and socket attachments, locator attachments, white locator, orange locator, $\mathrm{CBCT}$, Crestal bone resorption

\section{INTRODUCTION}

The distal extension base partial dentures problems are due to the absence of posterior abutments and the support mechanism between the periodontal ligament of the abutment tooth and the mucoperiosteum covering the edentulous ridge. ${ }^{(1)}$

The structures that supports mandibular distal extension removable partial denture differ markedly in their viscoelastic response to loading. The difference between the resilience of the residual ridge tissues $(500 \mathrm{pm})$ and that of the teeth $(20 \mathrm{pm})$ permitted by the periodontal ligaments presents a disparity of support that is in contrast to the uniform support of a tooth-supported removable partial denture. Hence the denture tends to rotate about its most distal abutments, inducing heavy tensional stresses on the abutment teeth and possible traumatization of the ridges. For this reason, it was advised to reduce base movement by enhancing and maintaining denture base support. ${ }^{(2,3)}$
The use of osseointegrate dental implants is one of the most successful treatment options for these situations. It was suggested to solve the problem of distal extension cases, so converting the distal extension base removable partial denture from a tooth-tissue supported prosthesis into a toothimplant supported one so solving the problem of different in resiliency. ${ }^{(4,5)}$

A critical aspect affecting the success or failure of an implant is the manner in which mechanical stresses are transferred from the implant to the bone. It is essential that neither implant nor bone be stressed beyond the long-term fatigue capacity. Any relative motion that can produce abrasion on the bone or progressive loosening of the implant should be avoided. ${ }^{(6)}$

One of the factors which influences the amount of force transferred to the implant is the choice of the attachment used in connecting the denture to the implant. ${ }^{(7)}$ The load transfer mechanism of the 
implant system is altered significantly by the type of attachment used.$^{(8)}$ The choice of the attachment used to retain the denture to the implants is dependent upon the retention required, jaw morphology, anatomy, mucosa covering the ridge, oral function, and patient compliance for recall. ${ }^{(9)}$

The Locator attachment system is a self-aligning and has dual retention (inner and outer retention). Its design has the benefits of the minimal requirement height $(3.7 \mathrm{~mm})$ and greater cross-section for strength. They are supplied in different colors; with a different retention value (white, orange and blue). The white housing has light retention (100gf), the orange has standard retention (500gf), and the blue has high retention (1000gf). And it has also additional features which are the extended range attachments, which can be used to correct implant angulations' up to 20 degree. ${ }^{(10)}$.

The ball and socket attachments consist of a titanium male unit and an easily replaceable rubber ring female unit that is retained in a metal retainer ring. It transfers the amount of stress to the abutments and provides excellent shock absorption during function. ${ }^{(11)}$

The question is which of the various Locator attachment system used to retain mandibular partial overdenture affect the magnitude of stresses transmitted to the implants thus affecting the bone height changes around the implants.

\section{MATERIAL AND METHODS}

Twelve class I mandibular partially edentulous patients with opposing full dentate maxillary arch were selected from the Outpatient clinic, Prosthodontic Department, Faculty of Dentistry, Ain shams University with proper oral hygiene, well educated regarding the use of over denture and free from any systemic diseases that affect Ossteointegration or bone resorption around the implant. Extra and intraoral examinations were done associated with the proper laboratory investigations including blood picture and blood sugar level.

Preoperative panoramic radiograph (1:1) was done to exclude patients with remaining roots or abnormal pathological condition then a diagnostic Cone Beam Computed Tomography (CBCT) images using i-CAT was done to evaluate bone volume (width) at the proposed implant site (first molar area)

All the steps of acrylic temporary partial denture construction were done starting with primary impression, secondary impression, followed by jaw relation, try-in for artificial teeth and final delivery of the acrylic partial denture. The partial denture was duplicated into clear acrylic resin model then the Model was finally scanned using CBCT machine and the DICOM data was processed to obtain STL file for the model.

Standard CBCT scanning procedures with standardized setting of $90 \mathrm{kV}, 6.3 \mathrm{~mA}$, an exposure time of $12 \mathrm{~s}$ and voxel size of $0.2 \mathrm{~mm}$ were followed for each patient. The scanning was performed by the same radiologist* For virtual planning of implant surgical guide, the resultant CBCT were imported into the implant planning software ${ }^{* *}$. The digital image segmentation was performed and the virtual implant was placed in the most optimal position (at the first molar area) according to the surgical and prosthetic design.

The designed virtual template was transferred as STL files and printed with a three- dimensional printing machine ${ }^{* * *}$. The metal sleeves for guided

\footnotetext{
* Planmeca promax 3D classic, Planmeca, Finland.

** Blue Sky Plan ${ }^{\circledR}$ V3, Blue Sky Bio, $n \circledR$ LLC, USA .

*** Form 1+, Form labs, USA.
} 
surgery were manually pushed into the respective knot.

All Patients should be under an umbrella of broad spectrum antibiotic* 24 hours before surgery and analgesics non-steroidal anti-inflammatory ${ }^{* *}$ those were taken every 12 hours after surgery for 5 days.

Surgical procedure of implant ${ }^{* * *}$ size $3.7 \times 8 \mathrm{~mm}$ insertion were done until completion of the osteotomy sites, platform was done using counter sink drill at a speed of 1000 RPM and a torque of $30-45 \mathrm{~N} / \mathrm{cm}$. The actual diameter of the countersink drill is $0.1 \mathrm{~mm}$ larger than the fixture platform. So that the top level of fixture needs to be located $0.5 \mathrm{~mm}$ below the marginal crestal bone level, moreover the drilling depth of the countersink was done. The implant was threaded until the implant top flushes with the alveolar bone surface. (Fig 1)

After three month from implant insertion, each patient was recalled for the insertion of super structure, fixture position was detected with the help of the surgical stent; a diagnostic probe was

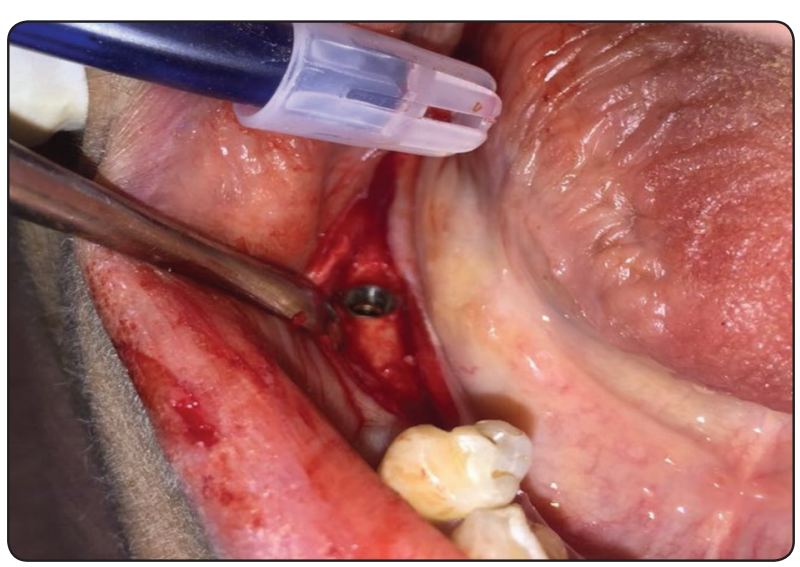

Fig. (1) Fixture inserted in place inserted through the hole of the surgical stent to make a bleeding point on the mucosa covering the proposed implant site. A surgical punch was used to expose the implant covering screw in the oral cavity then the covering screw was unthreaded, the healing abutment was threaded into the implant and tightened well using hex screw driver and the patient was given 1 week as a healing period.

The healing abutments were removed after verification of Ossteointegration; the field was properly cleaned using sterile saline solution.

The selected cases were randomly divided into three equal groups: Group I and Group II received a locator abutment; Group III received a ball and socket abutment. (Fig 2)

Primary impression ${ }^{* * * *}$ was made for all patients then poured into stone casts. The lower study cast was preliminary surveyed to determine the path of insertion and removal, and the needed mouth preparation and special trays were constructed.

Sharp diamond round bur no 3 was used to prepare mesial occlusal rest seats on enamel surface of the abutments. The rest seats were made saucer shaped with rounded angles. Sharp diamond stone with round end was used to prepare the guiding planes on enamel surface of the abutments. The preparation extends up to $2 \mathrm{~mm}$ of occluso-gingival height of distal surface of the abutments.

Secondary impression ${ }^{* * * * *}$ was made for the lower arch and poured in stone to produce the master cast that was finally surveyed. Undesirable undercuts were blocked-out using block-out wax and trimmed parallel to the path of insertion. Relief wax was also applied to the residual ridge areas to create space for the acrylic denture base.

\footnotetext{
* Augmentin 1g-Beecham MUP.

** Ibuprofen, Knoll, Ludwigshafen, Germany.

*** Dentium super line implants system Co., Ltd., Gangnam-gu, Seoul, Korea.

**** Cavex Holland BV.

***** LascodSpq,Sestofino(f1),Italy.
} 


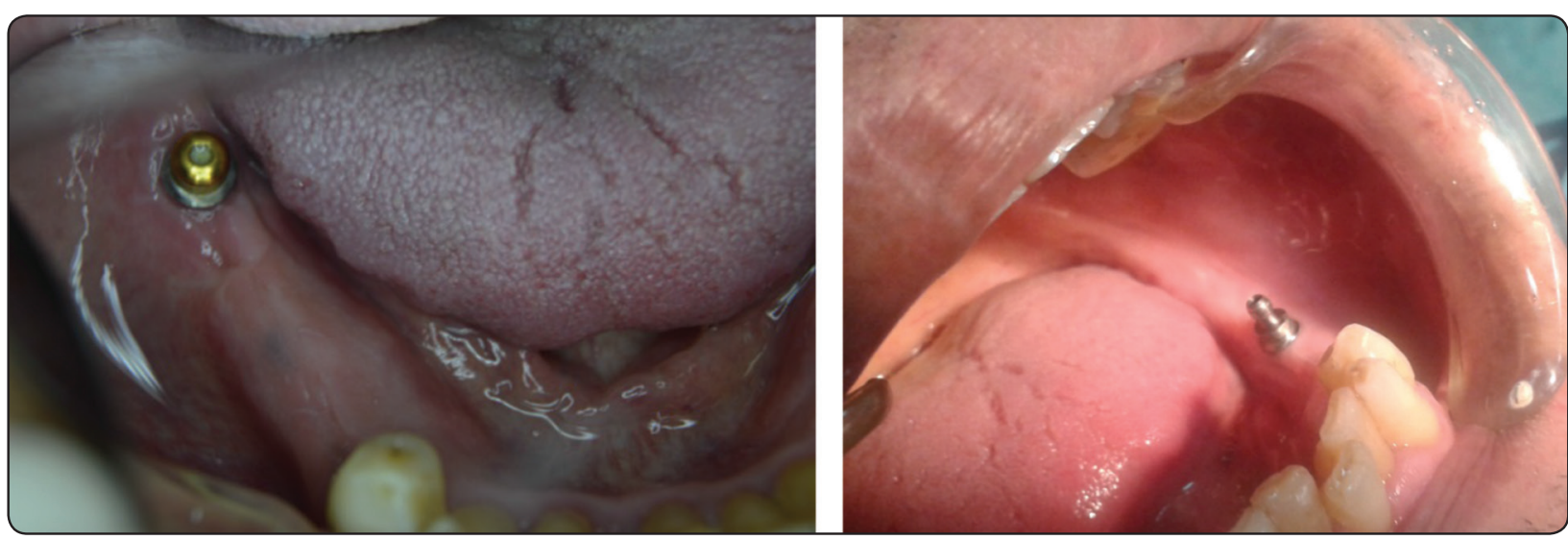

Fig. (2) Ball \& locator attachments tightened to the fixture.

Refractory cast was obtained by duplicating the modified master cast using agar-agar hydrocolloid duplicating material and investment as a casting material. Wax pattern of the partial denture framework was designed. The components of the design were RPI clasps on the distal abutment (occlusal rest on the first premolar), cingulum rests on the canines as indirect retainers and lingual bar as a major connector. The proximal plate was extended to the distolingual line angle and engaging about 1 $\mathrm{mm}$ of the bottom of the guiding plane. During wax up of the partial denture framework a hole was made in the denture base area around the metal housing to ensure complete seating of all components in the patients' mouth without interference.

Casting procedures were completed and partial denture frame work was obtained. Metallic framework was verified in the patient's mouth to check the fit of the occlusal rests indirect retainers and proper location of the major connector and clasps. (Fig 3)

Jaw relation following the interocclusal wax technique was made to mount the lower cast. Setting of Cross linked acrylic teeth* were done and the waxed up denture was tried in the patient's

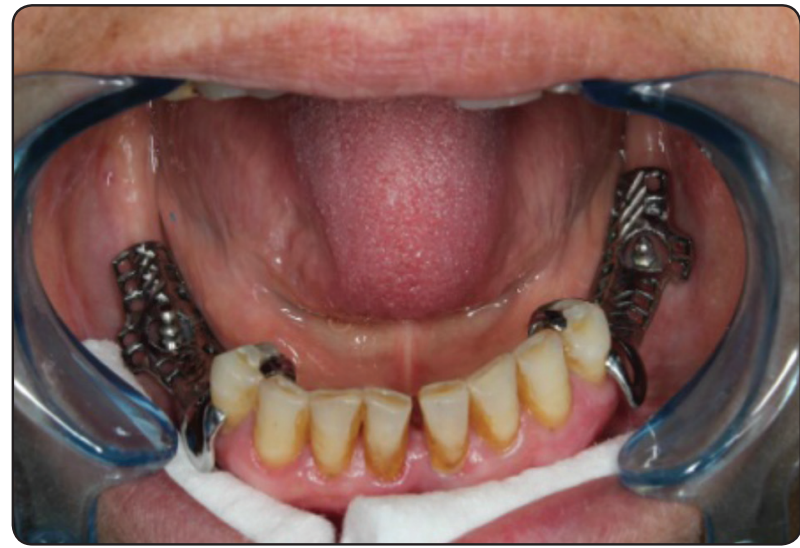

Fig. (3) Metallic framework in place

mouth. Denture processing was carried out in the usual manner.

The nylon ring was inserted on the attachment to block the under cuts and prevent the acrylic resin from entering this areas during pickup procedure, Then the metal housing with nylon cap was inserted on the attachment above the nylon ring.

Group I received a white locator attachment, Group II received an orange locator while Group III patients received a ball and socket attachments. The denture was checked to fit over the implants with their housings without interfering with the

\footnotetext{
* Acrostone medical and dental supplies.
} 
original fit of the denture. The attachment system were picked up into the mucosal surfaces of the overdenture using a Hard Pick-up material*. The patients were instructed to occlude on the dentures till the material set. Any excess material was removed and the denture was finished.

Patients in all groups received CBCT immediately after the implant loading, 6months, and 12 months after insertion of partial overdenture. Each implant was evaluated for the bone height changes around the implant. The implant shoulder was used as a reference point, and the distance to the first bone contact mesially and distally was measured from the CBCT for assessment of crestal bone level, peri-implant bone quality and bone surrounding implant apices. The radiographs were compared with base line radiographs. The marginal bone level was assessed at mesial and distal side of fixture on the radiographs. The height of the alveolar bone on mesial and distal sides of the implant was measured as follow: Average bone height $=($ Mesial bone height + Distal bone height) $/ 2$.

\section{RESULTS:}

The mean and standard deviation values were calculated for each group in each test. Data were explored for normality using Kolmogorov-Smirnov and Shapiro-Wilk tests, data showed parametric (normal) distribution.

Repeated measure ANOVA was used to compare between more than two groups in related samples. Paired wise sample t-test was used to compare between two groups in related samples. One-way ANOVA followed by Tukey post hoc test was used to compare between more than two groups in nonrelated samples.

The significance level was set at $\mathrm{P} \leq 0.05$. Statistical analysis was performed with $\mathrm{IBM} ®$
SPSS ${ }^{\circledR}$ Statistics Version 20 for Windows.

\section{I) Bone resorption results:}

\section{1) Effect of time:}

\section{a) Group I (White locator):}

No statistically significant difference was found between (BL-6m) and $(6 \mathrm{~m}-12 \mathrm{~m})$ where $(p=0.110)$.

The highest mean value was found in (BL-6m), while the lowest mean value was found in $(6 \mathrm{~m}-12 \mathrm{~m})$.

\section{b) Group II (Orange locator):}

No statistically significant difference was found between $(B L-6 m)$ and $(6 \mathrm{~m}-12 \mathrm{~m})$ where $(p=0.320)$.

The highest mean value was found in (BL-6m), while the lowest mean value was found in $(6 \mathrm{~m}-12 \mathrm{~m})$.

\section{c) . Group III (Ball and socket):}

No statistically significant difference was found between $(B L-6 m)$ and $(6 m-12 m)$ where $(p=0.130)$.

The highest mean value was found in (BL-6m), while the lowest mean value was found in $(6 \mathrm{~m}-12 \mathrm{~m})$.

\section{2) Effect of groups:}

\section{A) Bl-6m:}

A statistically significant difference was found between (Group I), (Group II) and (Group III) where $(p<0.001)$.

A statistically significant difference was found between (Group III) and each of (Group I) and (Group II) where $(p<0.001)$ and $(\mathrm{p}=0.001)$ respectively.

No statistically significant difference was found between (Group I) and (Group II) where $(p=0.084)$.

The highest mean value was found in (Group III) followed by (Group II), while the lowest mean value was found in (Group I).

* Secure HARD reline kit 3MTMESPETM, Germany. 


\section{B) $6 m-12 m:$}

A statistically significant difference was found between (Group I), (Group II) and (Group III) where $(p<0.001)$.

A statistically significant difference was found between (Group III) and each of (Group I) and (Group II) where $(p=0.001)$ and $(\mathrm{p}=0.005)$ respectively.

No statistically significant difference was found between (Group I) and (Group II) where ( $p=0.136)$.

The highest mean value was found in (Group III) followed by (Group II), while the lowest mean value was found in (Group I).

\section{DISCUSSION}

Prosthetic rehabilitation of class I partial edentulous mandible is one of the problems in removable prostheses. All attempts aimed at reducing the stresses transmitted to implant for their long term success. Recent advances in dental technology and materials evoked different locator attachments with a different retention value, the use of different attachment system will influence the stresses transmitted to the implant that will affect the bone height changes, which was the aim behind carrying out this investigation.

TABLE (1): The mean, standard deviation (SD) of bone resorption in different groups.

\begin{tabular}{|c|c|c|c|c|c|c|c|}
\hline \multirow{3}{*}{ Variables } & \multicolumn{7}{|c|}{ Bone resorption } \\
\hline & \multicolumn{2}{|c|}{$\begin{array}{c}\text { Group I } \\
\text { White locator }\end{array}$} & \multicolumn{2}{|c|}{$\begin{array}{c}\text { Group II } \\
\text { Orange locator }\end{array}$} & \multicolumn{2}{|c|}{$\begin{array}{c}\text { Group III } \\
\text { Ball and socket }\end{array}$} & \multirow[t]{2}{*}{ p-value } \\
\hline & Mean & SD & Mean & SD & Mean & SD & \\
\hline BL-6m & 0.47 & 0.04 & 0.54 & 0.02 & 0.76 & 0.05 & $<0.001 *$ \\
\hline $6 m-12 m$ & 0.35 & 0.03 & 0.45 & 0.05 & 0.66 & 0.07 & $<0.001 *$ \\
\hline p-value & \multicolumn{2}{|c|}{$0.110 n s$} & \multicolumn{2}{|c|}{$0.320 \mathrm{~ns}$} & \multicolumn{2}{|c|}{$0.130 n s$} & \\
\hline
\end{tabular}

*; significant $(p<0.05)$ ns; non-significant $(p>0.05)$

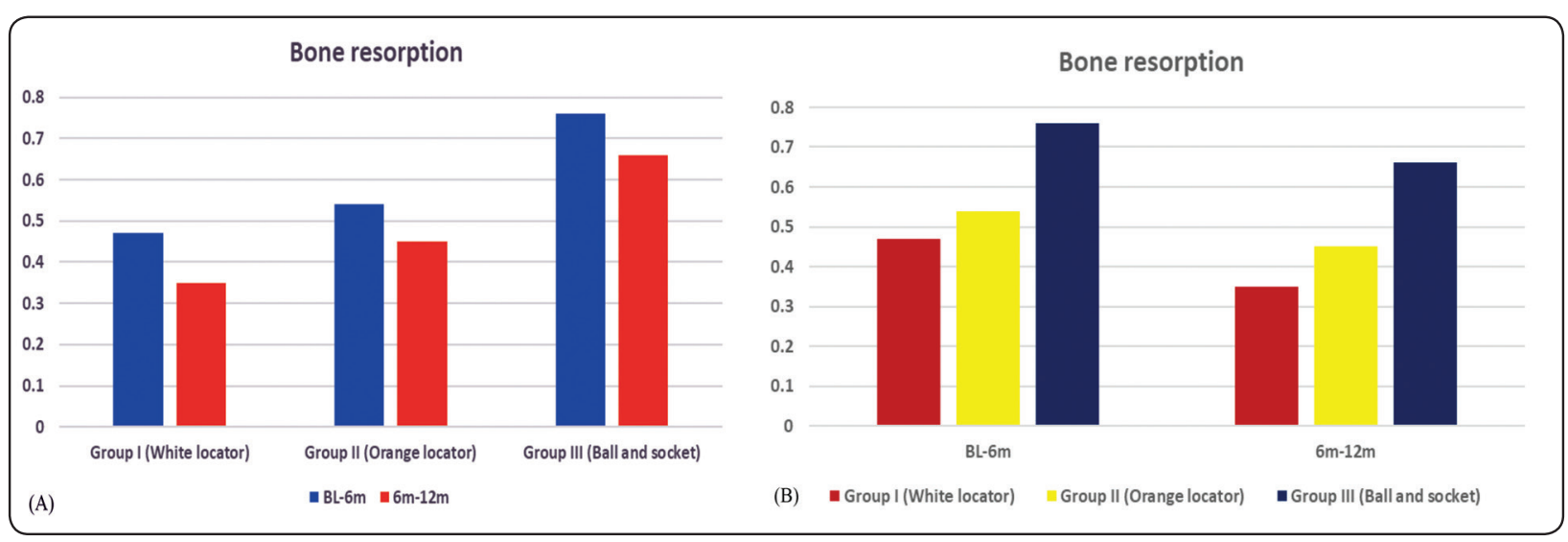

Fig. (4) Bar chart representing bone resorption for different groups. 
All the patients that were included in this study should had a period of at least six months from the time of the last extraction or any intra-oral surgery before the beginning of the study to make sure of the proper healing. ${ }^{(12)}$

The mandibular arch was selected for implant placement to help in solving some problems such as retention, stability and support of the superstructure. ${ }^{(13)}$

Proper patients' selection is very important for success of dental implant. Patients should be free from any systemic diseases (cardiac disease, diabetes mellitus, and debilitating diseases) that may affect the rate of bone resorption, gingival health, healing processes and the prognosis of implantoverdenture..$^{(14)}$

Also; patient with insufficient bone volume, Cases with abnormal ridge relations, or Parafunctional activities as bruxism in which the magnitude of force is increased, and the direction of the occlusal forces are more horizontal than axial to the implants. Angles' class I jaw relationship patients were selected to avoid abnormal forces which are exerted on the expected implant site, thus extra load on the implant can lead to bone loss, and higher rates of implant failure. Abnormal tongue size and/or position, high labial frenum or tonguetie require prosthetic and surgical treatment, all such cases were excluded. ${ }^{(15,16)}$

Computer guided surgery was used in this study which included virtual implants planning that allows the precise planning of implant positions on computer tomography scans and fabrication of accurate surgical guide that permits the surgeon to place implants precisely into planned positions allowing immediate loading of the prosthesis. ${ }^{(17)}$

In the implant selection, the implant designs are having sharp edged and high density threads to allow fast and successful ossteointegration. ${ }^{(18)}$

Cone beam radiograph was used to asses alveolar bone height and its loss around implants.
Cone beam was used as it provide accurate 3D image, with minimal dose of radiation compared to conventional CT system, inexpensive, and limited scan time. ${ }^{(19)}$

Success of dental implant treatment mainly depends on the sustainable long-term health of soft and hard peri implant tissues. Assessment of mobility, pain, infection, inflammation and marginal alveolar bone loss are all considered as useful implant success criteria. Specific attention has been directed towards post-operative radiographic assessment of marginal alveolar bone loss around implants by serial radiographs. Vertical marginal bone loss at the peri-implant surfaces should not exceed 1-2 $\mathrm{mm}$ during the first year of function and $0.2 \mathrm{~mm}$ thereafter. ${ }^{(20)}$ Bone loss appeared to be within acceptable limits in the groups during follow up period(less than $1 \mathrm{~mm}$ during first year).

The clinical outcome of the present study demonstrated significant differences in the bone height changes around the implant between both locator attchments and ball and socket attchments in the Kennedy class I cases after 12 months follow up. ${ }^{(21)}$

Such results was can be contributed to the stress distribution of the attachment systems, This is possibly related to its low profile design and to the rotational pivoting character of its abutment that is also advocated in combination with close-to-parallel internal-connection implants to lower the rotational centre and to potentially reduce the lateral forces. The vertical resilience of the locator attachment may also be a factor as it allows movements in both the vertical plane as well as the hinge axis.

Such results are in acceptance with a previous finite element based study (Taftazani et al) where ball and locator attachments were compared and locator showed better results to the ball attachments in terms of reducing stresses on the implant body and its supporting structures which may be due to the smaller height and wider diameter of the locator attachment than ball and socket attachment, 
such geometrical design allows better dissipation of stressses when occlussal load was applied. ${ }^{(22)}$

The resilience of the locator is achieved through a space of $0.2 \mathrm{~mm}$ which is designed to allow for vertical resilience and hinging in any direction providing a higher amplitude movement of the prosthesis; anteroposteriorly, laterally and intrusive. ${ }^{(23)}$

Also the locator has high-density resin cap that is originally designed to be incorporated into the denture base to help managing stresses. It acted as if it helped by carrying a big share of stresses to protect the simulated supporting structures; cortical and cancellous bone as well as the implant body from being stressed. The locator attachment therefore was reported to offer a significant advantage with reduction in the problems associated with rapid component wear and failure. ${ }^{(24)}$

The findings of the present study may support previous opinions that considered the locator attachment advantageous biologically and mechanically. ${ }^{(25)}$ and that ball attachments should not be the attachment of choice in cases of nonparallel implants..$^{(26,27)}$

The resutls of this study show no significant difference between group I and II but group II show higher bone resorption than group I and this is may be due to the higher resiliency of the white attachment that will act as shock absorber and will dissipates the applied occlussal load, inaddition to that the white attachment has lower retention value that allow easier insertion and removal of the prosthesis by the patient that will results in less stresses transmitted to both implant and its supporting structure.

\section{CONCLUSION}

The current study concluded that locator attachments with different retention value provides better preservation of crestal bone than ball and socket stud attachment, where the white locator attachment show transmits less stress to to the abutment resulting in reducing the amount of bone loss around the implants than orange locator when used in implant supported classI mandibular partial over denture thus white locator with low retention value can be used with patient having low bone density D3or D4 or increased applied forces due to the opposing occlusion or parafunctional habits

\section{REFERENCES}

1. Holmes, J. B.: Influence of impression procedures and occlusal loading on partial denture movement. 1965. The Journal of prosthetic dentistry 2001, no 86,pp. 35-41.

2. J. F. Bates and M. Addy, "Partial dentures and plaque accumulation,” J. Dent. 1978, vol. 6, no. 4, pp. 285-293,.

3. F. Verri, E. Pellizzer, E. Rocha, and J. Pereira, Influence of Length and Diameter of Implants Associated With Distal Extension Removable Partial Dentures2007, vol. 16..

4. Jang, Y.; Emtiaz, S.; Tarnow, D. P.: Single implant-supported crown used as an abutment for a removable cast partial denture: a case report. Implant dentistry 1998,vol 7,pp.199-204

5. Gutlapalli, N. J.; Reddy, D. M.; Mikkilineni, H.: Implantsupported overdentures. Journal of the New Jersey Dental Association 2013, vol 84,pp 24-7.

6. Meijer HJA, Kuiper JH, Starmans FJM and Bosman FJM: Stress distribution around dental implants: influence of superstructure, length of implant and height of mandible. J Prosthet Dent. 1992;vol68:pp.96-102.

7. Heckmann SM, Winter W.: Overdenture attachment selection and the loading of implant and denture-bearing area. Part 2: A methodical study using five types of attachment Clin. Oral Impl. Res. 2001; vol 12; pp.640-647.

8. H.J. Chun, D.N. Park, C.H. Han, S.J. Heo, M.S. Heo, J.Y. Koak, Stress distributions in maxillary bone surrounding overdenture implants with different overdenture attachments, Journal of Oral Rehabilitation2005 vol 32/3:pp. 193-205.

9. Evtimovska E, Masri R, Driscoll CF and Romberg E.: The change in retentive values of locator attachments and Hader clips over time. J Prosthodont ,2009; vol 18:p.479.

10. Schneider AL, Kurtzman GM. Restoration of divergent free-standing implants in the maxilla. J Oral Implantol 2002; vol 28:pp.113-6. 
11. Winkler S, Piermatti J, Rothman A, Siamos G. An overview of the O-ring implant overdenture attachment: Clinical reports. J Oral Implantol 2002; vol 28:pp.82-6.

12. El-Guindy M., E.-T. M., Abdel Razzak Y.: Longitudinal evaluation of tricalcium phosphate ceramic combined with tetracycline HCL root conditioning in treatment of periodontal osseous defects. Med. Cairo Univ. 1996, pp.195-205.

13. Santiago Junior JF, P. E., Verri FR, de Carvalho PS.: Mater Sci Eng C Mater Biol Appl. 2013, vol 33,p.14.

14. Ohrnell, L. O., Hirsch, J. M., Ericsson, Iand Bränemark: Single teeth rehabilitation using ossteointegration, A modified surgical and prosthetic approach. Quintessence international 1988,pp. 871-872.

15. Becker, W.; Becker, B. E.: Replacement of maxillary and mandibular molars with single endosseous implant restorations: a retrospective study. The Journal of prosthetic dentistry 1995, vol 74,pp. 51-55.

16. Colomina, L. E.: Immediate loading of implant-fixed mandibular prostheses: a prospective 18-month follow-up clinical study--preliminary report. Implant dentistry 2001, vol 10, pp. 9-23.

17. Ilser Turkyilmaz, Caroline Corrigan Eskow and Gokce Soganci: CAD/CAM Technology in Implant Dentistry. Current concepts in of dental implantology ISBN 978953-51-1741-4, Pub February 25, 2015.

18. Enkling, N.; Johren, P.; Klimberg, T.; Mericske-Stern, R.; Jervoe-Storm, P. M.; Bayer, S.; Gulden, N.; Jepsen, S.: Open or submerged healing of implants with platform switching: a randomized, controlled clinical trial. Journal of clinical periodontology 2011, vol 38, pp. 84-374.

19. K Kamburo glu, S Murat, C Kılıç, S Y“ uksel, H Avsever, A Farman and W C Scarfe: Accuracy of CBCT images in the assessment of buccal marginal alveolar peri-implant defects: effect of field of view; Dentomaxillofacial Radiology, 2014.

20. Porter, J.A. and J. A. von Fraunhofer: "Success or failure of dental implants? A literature review with treatment considerations." Gen Dent 53(6): 423-432; quiz 433, 446, 2005.

21. Van Assche, N., Collaert, B., Coucke, W. \& Quirynen, M. : Correlation between early perforation of cover screws and marginal bone loss: a retrospective study. Journal of clinical periodontology 2008, pp. 76-79.

22. El-Taftazani.I et al. Locator Attachment versus Ball Attachment: 3-Dimentional Finite El ement Study. E.D.J. 2011,Vol. 57, No. 2.

23. Evtimovska E, Masri R, Driscoll CF, Romberg E. Thechange in retentive values of locator attachments and hader clips over time. J Prosthodont. 2009 Aug;vol 18(6): pp. 479-483.

24. Fromentin O, Lassauzay C, Abi Nader S, Feine J, de Albuquerque Junior RF. Testing the retention of attachments for implant overdentures - validation of an original force measurement system. J Oral Rehabil. 2010 Jan;vol 37(1): pp. 54-62.

25. Kurtzman GM. The locator attachment: Free standing versus bar overdentures. Dent Labor Int plus, Feb. 2009; vol $1 ;(1), p p .20-23$.

26. Walton JN, Huizinga SC, Peck CC. Implant angulation: a measurement technique, implant overdenture maintenance, and the influence of surgical experience. Int J Prosthodont 2001;vol 14:pp. 523-530.

27. Alsiyabi AS, Felton DA, Cooper LF. The role of abutment attachment selection in resolving inadequate interarch distance: a clinical report. J Prosthodont 2005; vol 14(3):pp. 184-190. 